\title{
Various Types of Interferences during Sample Analysis in Atomic Absorption Spectrometry
}

\author{
Ashish Chauhan ${ }^{1 *}$ and Bharti Mittu² \\ ${ }^{1}$ National Institute of Pharmaceutical Education and Research, Mohali, Punjab, India \\ ${ }^{2}$ Punjabi University, Patiala, Punjab
}

\section{Introduction}

Atomic Absorption Spectroscopy (AAS) is versatile analytical technique that has numerous applications in bio-physics, pharmacology, toxicology, environmental science and clinical studies. Atomic absorption spectrometry is very useful in different areas of chemistry:

1. Water analysis for $\mathrm{Ca}, \mathrm{Mg}, \mathrm{Fe}, \mathrm{Si}, \mathrm{Al}, \mathrm{Ba}$ content

2. Clinical screening of metals in biological fluids as whole blood, plasma, serum, $\mathrm{Ca}, \mathrm{Mg}, \mathrm{Li}, \mathrm{Na}, \mathrm{K}, \mathrm{Fe}$ and other toxicology studies.

3. Pharmaceutical procedures like research and development, quality control, manufacturing processes, pharmacological studies, minute quantities of a catalyst that remain in the final drug product are analyzed.

4. Analysis of additives in lubricating oils and greases, metals like $\mathrm{Ba}, \mathrm{Ca}, \mathrm{Na}, \mathrm{Li}, \mathrm{Zn}, \mathrm{Mg}$ can be screened.

5. Analysis of animal feedstuffs e.g. $\mathrm{Mn}, \mathrm{Fe}, \mathrm{Cu}, \mathrm{Cr}, \mathrm{Se}, \mathrm{Zn}$ is analyzed in the sample.

Even though AAS is a popular spectroscopic technique but it has some disadvantages due to various chemical and physical interferences during the analysis. Some of the chemical and physical interfering factors are discussed below.

\section{Chemical Interference}

1.1a. The volatile compounds are lost during drying or predominantly during the ash formation. Analytes cause interference by readily forming covalent chlorides in the presence of excess chloride ions that may cause the analyte to form a volatile chloride which vaporize before it can be decomposed to the atomic form. These kind of losses due to vaporization degrade analytical sensitivity. 1.1b. If the analyte forms several stable compounds than interference dominates. This results in an atomic signal with multiple peaks instead of a single coherent peak. The analyte is not lost during drying or ash formation stage and atomic concentration of interest is associated with two or more compounds with different thermal stabilities.

1.1c. Interference prevails while formation of a thermally stable compound that is not decomposed to the atomic form during the atomization step. An example is carbide formation of barium, vanadium, molybdenum and titanium. This interference can be reduced by using pyrolytic coated graphite tubes or platforms. Note that some elements readily form intractable carbides even in the presence of pyrolytically coated graphite. Examples are tantalum, tungsten.

\section{Physical Interferences}

1.2a Viscosity of the sample interferes from being injected into the tube. Samples with low viscosities suffer from creep. This can result in some of the sample material not reaching the furnace. Solutions of this interference is addition of acid content and some organic solvents (i.e., Cyclohexane, MIBK).

1.2b.The extent to which a solution spreads over the tube wall surface depends on the viscosity and wetting characteristics. Differences in spreading across the tube wall surface can significantly affect the absorption signal due to residence time of atoms within the observation zone varying with distance from the centre of this zone to where the atomization occurs.

Keeping in mind the following interfering factors during the sample analysis and implementing better background correction techniques, effective results can be obtained.
*Corresponding author: Ashish Chauhan, National Institute of Pharmaceutical Education and Research, Mohali, Punjab, India, Tel: 9464616773; E-mail: aashishchauhan26@gmail.com

Received December 01, 2014; Accepted December 02, 2014; Published December 05, 2014

Citation: Chauhan A, Mittu B (2014) Various Types of Interferences during Sample Analysis in Atomic Absorption Spectrometry. J Textile Sci Eng 4: 176. doi:10.4172/2165-8064.1000176

Copyright: (C) 2014 Chauhan A, et al. This is an open-access article distributed under the terms of the Creative Commons Attribution License, which permits unrestricted use, distribution, and reproduction in any medium, provided the original author and source are credited. 